\title{
Can Law Foster Social-Ecological Resilience?
}

\author{
Ahjond S. Garmestani ${ }^{1}$, Craig R. Allen ${ }^{2}$ and Melinda H. Benson ${ }^{3}$
}

\begin{abstract}
Law plays an essential role in shaping natural resource and environmental policy, but unfortunately, many environmental laws were developed around the prevailing scientific understanding that there was a "balance of nature" that could be managed and sustained. This view assumes that natural resource managers have the capacity to predict the behavior of ecological systems, know what its important functional components are, and successfully predict the outcome of management interventions. This paper takes on this problem by summarizing and synthesizing the contributions to this Special Feature (Law and Social-Ecological Resilience, Part I: Contributions from Resilience 2011), focusing on the interaction of law and socialecological resilience, and then offering recommendations for the integration of law and social-ecological resilience.
\end{abstract}

Key Words: adaptive governance; adaptive management; law; social-ecological resilience

\section{INTRODUCTION}

Law plays an essential role in shaping natural resources and environmental policy. Unfortunately, many of the environmental laws now in place were developed around the prevailing scientific understanding in the 1960s and 1970s that the natural world existed within an envelope of predictability that there was a "balance of nature" that could be managed and sustained (Craig 2010). This view assumes that natural resource managers have the capacity to predict the behavior of ecological systems, know what the important functional components are, and successfully predict the outcome of management interventions (Benson and Garmestani 2011a). These assumptions stand in stark contrast with reality, and the tenets of resilience theory. Resilience theory was developed over the past four decades to explain abrupt changes in socialecological systems. Resilience is the capacity of a system to withstand internal and/or external change yet remain within the same regime (Holling 1973). If a system is unable to withstand change, the system may shift into an alternative regime with a different set of processes and structures. Key elements of resilience theory include the critical role of crossscale dynamics and disequilibrium in social-ecological systems.

How can this dynamic, non-equilibrium centered understanding of social-ecological systems be integrated into environmental decision-making? This Special Feature (Law and Social-Ecological Resilience, Part I: Contributions from Resilience 2011) takes on this question and focuses on the interaction of law and social-ecological resilience. Climate change, resource consumption patterns, deteriorating ecosystems and concomitant loss of services, the demand for energy, and aging infrastructure all have the capacity to trigger rapid nonlinear change, as well as social and economic instability. Uncertainty in these factors challenges traditional approaches to governance, which often relies on the assumption that historic data can be used to predict the future. Although resilience is an emergent property of socialecological systems that is increasingly recognized as a critical consideration for sound environmental management, current environmental law is largely too inflexible to allow us to manage for resilience. Legal reform in response to new information is difficult to achieve under our current legal paradigm, because the organizational bureaucracy is conservative and resistant to change (Lazarus 2004). Complex systems are typically characterized by a regime of variability within which they oscillate (de Loe and Plummer 2010), but can exhibit unpredictable behavior when resilience is exceeded. When resilience is exceeded, a system will reorganize around a different set of processes, producing different goods and services for humankind. Alternative states of systems are sometimes less desirable for humankind, but may be very resilient, and exhibit hysteresis. In such cases, changing the system back to the desired state may be difficult, or functionally impossible. The irreversible nature of many ecological changes necessitates that laws be reformed to proactively address potential harms before they occur, rather than attempting to "restore" ecosystem function and services after they have been destroyed (Lazarus 2004). This presents a further complication, because emerging environmental challenges (e.g., cross-boundary water governance, climate change) are not easily addressed within the current legal framework. Even if problems can be identified prior to systemic response (i.e., regime changes), the solutions require frequent recalibration of the laws and policies used to address the environmental problem (Ruhl 1999). A legal system that 
is linear and largely static is ill-suited for the nonlinear dynamics of linked social-ecological systems. Science is a process; but while the law seeks resolution, a legal system that sets a rule and does not revisit and adjust the rule following assessment of the rule's effects is incompatible with managing for resilience (Cosens 2008).

The articles and responses in this Special Feature explore several challenges associated with the challenges noted above, and can be divided into three main themes. The first theme relates to adaptive capacity. Adaptive capacity encompasses the ability to experiment, learn and innovate in response to changing conditions in social-ecological systems (Armitage and Plummer 2010a). Cosens and Williams (2012) explore adaptive capacity via an analysis of the historical development of the management of the Columbia River basin. The basin is managed jointly by the United States and Canada, but the current treaty between the two countries is under review. Adaptive management has been utilized on the U.S. side of the basin, but it has not been successful. Cosens and Williams argue that although adaptive management is a key aspect to fostering resilience, it is only one piece of the institutional changes necessary for resilience-based governance. Walker (2012) offers that if the rules for changing the rules (i.e., law for adaptation) can be agreed upon beforehand, then the mismatch between the law and ecosystems can be reduced. Walker also contends that the capacity for transformation is likely more important than adaptive management in a world of accelerating change, and concludes by making a plea for more research focused upon understanding, defining and implementing adaptive governance.

Green et al. (2013) provide an analysis of the European Union Water Framework Directive (WFD) through a resilience lens. The WFD was designed to promote the sustainability of water resources, and while it did not explicitly incorporate resilience science into its development, resilience is a necessary attribute for sustainability. Green et al. (2013) find that while the WFD does not provide for adequate feedback from monitoring results and also suffers from a lack of enforcement, it does provide scale-appropriate governance (i.e., delegation of control to local levels) and cross-scale information flow. Thus, the WFD has promise to manage for resilience, but would require reform with respect to monitoring and enforcement. Armitage (2013) makes the key observation that legal and regulatory frameworks need to be adaptive, but also maintain legitimacy. This is no easy task, and is the subject of a new wave of research on law and resilience that is essential if resilience science is to manifest a transition to sustainability. The lynchpin is likely the reform of administrative law, at least for U.S. and EU law, and this area should be a focus of research moving forward (Armitage 2013).

The second theme is the importance of institutional design and legitimacy. Garmestani and Benson (2013) offer a resilience- based framework for the governance of social-ecological systems based upon integrating principles from resilience theory with principles from reflexive law. At its core, the framework requires organizational learning, cross-scale linkages and generation of adaptive capacity as a means for governing in a more flexible, iterative and adaptive manner. Cumming (2013) recognizes that mismatch between scales of ecosystems and the organizations responsible for managing them can result in decreased resilience of a system. So, a system of governance should account for scale and have the necessary flexibility to account for resilience, while at the same time having the necessary accountability under the law. Although reflexive law may not ultimately be the answer to the problem of managing for resilience, Cumming sees the potential in the framework offered by Garmestani and Benson. Cumming recognizes such a framework has potential because it allows for and encourages innovation at local scales, with the capacity to scale up, which could offer a solution to scale mismatches.

A critical element of institutional design for resilience relates to the need for the law to be more responsive to the cross-scale dynamics of social-ecological systems. Ruhl (2012) analyzes panarchy theory and the law, and argues that while the theory is "on point" for the no-analog future, it will not gain traction unless it can be codified into laws and regulations. Panarchy theory describes hierarchical systems where control is not only top down, but also bottom up (Gunderson and Holling 2002). Thus, panarchy theory is useful for explaining the capacity for nonlinear change in linked social-ecological systems. Operationalizing panarchy theory will require adaptively managing legal, ecological and social systems. Ruhl concludes that panarchy theory does not provide lawyers with a guide for how to achieve this, as panarchy theory was developed without lawyers and explicit consideration of the law. Thus, panarchy theorists, lawyers and decision-makers must develop a path forward to translate panarchy into law. Holling (2012) expresses hesitation about the capacity of law to be flexible and manage for the dynamics of linked social-ecological systems. Holling suggests the way forward is to encourage workshops that launch locally designed collaborative experiments that have the capacity to cross scales and manifest change.

The third theme relates to the interface of resilience thinking with existing resource allocation regimes and environmental protections. Benson (2012) makes the observation that in the United States, the Endangered Species Act (ESA) has been the primary driver behind ecological restoration efforts focused upon ecosystem management and tends to focus management too narrowly. In order for ESA to make the shift from restoration to resilience, ESA would require several reforms, including a shift to a systems-based approach, integrated governance and proactive management of socialecological systems. Gunderson (2013) agrees with Benson and 
argues that ESA limits resilience-based management of ecosystems because it is based upon an outdated conception of nature ("balance of nature"), as well as the rigidity of the law as it applies to individual species that are in peril.

\section{RECOMMENDATIONS}

It is likely that we will have to reform our current legal frameworks in the United States, Europe and elsewhere in order to account for the increasing nonlinearities in system dynamics that are probable in light of accelerating global environmental change. It is possible that some current laws have the capacity to be reformed in order to account for resilience, and therefore provide the capacity for improved environmental governance (see Benson and Garmestani 2011b). In other cases, wholesale change in the legal regime will be necessary as we move forward (see Flournoy and Driesen 2010, Ruhl 2011, Arnold and Gunderson 2013). Based on the articles in this feature and the integration of the existing literature on the interplay of resilience and law, we make these recommendations for the integration of law and socialecological resilience:

\section{Utilize adaptive management and adaptive governance}

Adaptive management is the process whereby management actions that have uncertain outcomes, are undertaken in an explicit framework that reduces uncertainty. Adaptive management was developed as a way to probe system behavior, and thus learn about system dynamics, while allowing management to occur. For sound environmental governance, networks of private and public entities communicate and share information (Armitage and Plummer $2010 b$ ). In its current form, law does not have the capacity to account for resilience, other than in piecemeal fashion. Quite simply, this arrangement may not suffice as we move forward, because in order to conduct sound environmental governance, it is important to understand how the scale of interest interacts with scales above and below (e.g., cross-scale interactions) (Anderies et al. 2006). Further, adaptive governance builds upon adaptive management and revolves around decentralized governance, stakeholder input and informal networks. The criticisms of this perspective are that it fails to account for law and formal institutions, avoids difficult decisions between outcomes and values, and results in ineffective, unimplemented or undoable governance actions (Arnold 2011). Thus, in order to integrate law and social-ecological resilience, adaptive governance could be incorporated into formal legal frameworks, which will require legal reform.

\section{Reform of administrative law: "front-end" to "back- end"}

Administrative law governs the process of agency decisionmaking to implement substantive law. It is through administrative law that an agency might be given authority to, for example, coordinate and share information with other entities at the same or another hierarchical level. A more fundamental problem with administrative law is the focus upon procedural rules (Karkkainen 2005). Thus, the process of deciding environmental regulations has flexibility, but once regulations are agreed upon, regulations are rigid in nature ("front-end"). By setting environmental regulations at the front-end, the legal process guarantees certainty for legal and economic interests. While having a formalized legal process is important for enforceability, it makes it difficult to manage for resilience in light of our understanding of the dynamics of linked social-ecological systems. Therefore, the inability of administrative law to account for uncertainty in the management process, in essence, means the law is at odds with science (Karkkainen 2005).

Shapiro and Glicksman (2004) suggest that, in order to better accommodate adaptive management, "back-end" adjustments to regulation could serve as a more effective mechanism. The back-end adjustment process is viewed as an improvement to the "guess work that is involved in rationalizing regulations at the front-end of the process" (Shapiro and Glicksman 2004). Shapiro and Glicksman (2004) recognize that a regulatory system that has some flexibility, in appropriate cases, has the potential to generate the necessary conditions to manage for resilience. This idea has promise, as resilience-based management requires an iterative process that improves management as the process proceeds (i.e., back-end adjustments). For "back-end" adjustments to be incorporated into the regulatory framework, Shapiro and Glicksman (2004) argue that administrative laws need to be amended via deadline extensions, exceptions, waivers, or variances. A notice and comment process is the recommended mechanism for backend adjustments, but not in isolation (Shapiro and Glicksman 2004). In addition to a notice and comment process, Shapiro and Glicksman (2004) contend that Congress would also need to require agencies to establish electronic dockets and create annual reports on the back-end adjustment process. Thus, in order to account for resilience in environmental management, resilience science will need to be linked to enforceable standards that have some capacity for adaptation (Benson and Garmestani 2011a).

\section{Require communication, monitoring and intermediaries}

Institutional interplay refers to the interaction between institutions at multiple scales (Wandel and Marchildon 2010). The problem of fit manifests when a system is poorly matched with the institutions tasked with its management (Wandel and Marchildon 2010). For instance, there can be a spatial mismatch between exclusive economic zones and marine systems, where overfishing in one country has impacts on fish stocks in the exclusive economic zone of another country (Wandel and Marchildon 2010). The problem here is that national level institutions do a poor job of managing a natural resource (e.g., fish) that has no regard for jurisdictional 
boundaries (Wandel and Marchildon 2010). In some cases temporal mismatch is the problem (Wandel and Marchildon 2010). For example, Canadian fisheries policy reacted too slowly to early indications of decline in the North Atlantic cod fishery which ultimately led to its collapse in 1992 (Walters and Maguire 1996, Wandel and Marchildon 2010).

Institutions are distinct from organizations, in that organizations typically have personnel, offices, budgets and a legal personality (Young et al. 2008). Within this context the U.S. legal system is an institution with a set of rights, rules and procedures, while natural resource agencies are organizations bound to fulfill their mandate within the purview of the U.S. legal system. In making this distinction, Young et al. (2008) set the tone for their recent book, but many of their recommendations for institutions apply to organizations. For example, there is a gap between science and policy, and Young et al. (2008) advocate for bridging this gap via "knowledge brokers" that can bridge the chasm between science and policy. Kofinas (2009) asserts that linkages between organizations, institutions and intermediaries (e.g., networks) have the capacity to foster resilience in social-ecological systems. For example, the institutional failures during Hurricane Katrina are attributed to the lack of communication between scales of governance ranging from local to federal (Kofinas 2009).

\section{Account for scale}

The rigidity of legal institutions and organizations makes it difficult to account for cross-scale environmental problems (e.g., biodiversity loss) (Benson and Garmestani 2011b). Accounting for scale mismatches between management and the systems they are tasked with managing, is one of, if not the critical issue in managing for resilience (Garmestani et al. 2009). The issues with scale mismatches have a long history of leading to failures in natural resources management. For example, in 1977, Canada declared an exclusive zone of fishing for northern cod, which even with these protections resulted in a ban on northern cod fishing after the fishery collapsed in 2002 (Dietz et al. 2003). The fishery went into precipitous decline even though aggregated information on the fishery indicated that the fishery was recovering. The lesson learned was that there were smaller (i.e., local) scale indicators that the fishery was not recovering in the manner that large-scale, aggregated information suggested (Dietz et al. 2003). Scale matters, and there is a critical need to monitor and model at multiple scales for sound environmental governance (Anderies et al. 2007).

It is our contention that the critical variable, and the most difficult one to account for when building adaptive capacity, is scale. To illustrate this problem, Bohensky et al. (2010) provide a detailed example of the problems associated with marine governance. Hughes et al. (2007) identified three major processes as threats to the Great Barrier Reef, including: overharvesting of marine resources, declining water quality due to land-use impacts adjacent to watersheds and climate change. Each of these threats to the Great Barrier Reef represents problems at multiple scales (Bohensky et al. 2010). For example, overharvesting of marine resources results from local pressure but also international demand; water quality is influenced by national and international demand for agricultural and mineral commodities, national and state environmental policies, and the demands of the regional economy; and climate change impacts range from global to local scales (Bohensky et al. 2010). Complicating this issue further is the fact that the major threats to a social-ecological system are managed by different organizations operating at different scales (Conroy et al. 2003). For example, fisheries are managed at the state level, while national marine waters and reefs fall under the jurisdiction of the Great Barrier Reef Marine Park Authority; water quality is addressed by the Reef Water Quality Protection Plan, which involves all levels of government, as well as industry organizations, indigenous groups and scientists; and climate change is managed by the Great Barrier Reef Marine Park Authority and the Australian Department of Climate Change (Bohensky et al. 2010). Since we are faced with processes operating at multiple scales, this presents a great challenge for governance of complex adaptive systems. This illustration of the cross-scale nature of the processes affecting the Great Barrier Reef illuminates the importance of scale when considering management actions (Bohensky et al. 2010).

\section{CONCLUSION}

An adaptive approach is difficult to implement due to legal (e. g., administrative law) and organizational barriers (e.g., lack of communication between management entities) that are not in concert with ecological reality (Ruhl 2005), but managing for resilience (Allen et al. 2011) is critical, and law plays an essential role. Laws, like management or governance, should, where appropriate, be implemented experimentally. In other words, we call for an "adaptive law" approach (Arnold and Gunderson 2013). Ilg (2010) contends that the standard for environmental law in the future should turn on the capacity of the proposed framework to adapt in the face of new information about flaws in the legal system. A methodology that has great potential would be based in large part upon resilience theory, adaptive management and adaptive governance (Karkkainen 2005). In essence, what is needed is an iterative approach that has feedbacks built-in between the ecological and the social system, which allows for policy to evolve in response to policy experiments, and laws to evolve in response to legal experiments, and not past assumptions about the system of interest (Garmestani and Allen 2014). Here, laws can be applied within an adaptive or structured decision-making framework, and the utility and effectiveness of the laws can be assessed through monitoring. Too often laws are static; we envision a much more dynamic system of laws in an experimental framework. 
Responses to this article can be read online at: http://www.ecologyandsociety.org/issues/responses. $\mathrm{php} / 5927$

\section{Acknowledgments:}

The views expressed in this paper are those of the authors and do not necessarily represent the views or policies of the U.S. Environmental Protection Agency. The Nebraska Cooperative Fish and Wildlife Research Unit is jointly supported by a cooperative agreement between the United States Geological Survey, the Nebraska Game and Parks Commission, the University of Nebraska-Lincoln, the United States Fish and Wildlife Service and the Wildlife Management Institute.

\section{LITERATURE CITED}

Allen, C. R., G. S. Cumming, A. S. Garmestani, P. D. Taylor, and B. H. Walker. 2011. Managing for resilience. Wildlife Biology 17:337-349.

Anderies, J. M., B. H. Walker, and A. P. Kinzig. 2006. Fifteen weddings and a funeral: case studies and resilience-based management. Ecology and Society 11(1): 21. [online] URL: http://www.ecologyandsociety.org/vol11/iss1/art21/

Anderies, J. M., A. A. Rodriguez, M. A. Janssen, and O. Cifdaloz. 2007. Panaceas, uncertainty, and the robust control framework in sustainability science. Proceedings of the National Academies of Sciences 104:15194-15199. http://dx. doi.org/10.1073/pnas.0702655104

Armitage, D. 2013. Resilience and administrative law. Ecology and Society 18(2): 11. http://dx.doi.org/10.5751/ ES-05611-180211

Armitage, D. and R. Plummer. 2010a. Adaptive capacity and environmental governance. Springer, Heidelberg, Germany. http://dx.doi.org/10.1007/978-3-642-12194-4

Armitage, D. and R. Plummer. 2010b. Adapting and transforming: governance for navigating change. Pages 287-302 in D. Armitage and R. Plummer, editors. Adaptive capacity and environmental governance. Springer, Heidelberg, Germany. http://dx.doi.org/10.1007/978-3-642-12194-4_14

Arnold, C. A. 2011. Fourth-generation environmental law: integrationist and multimodal. William and Mary Environmental Law \& Policy Review 35:771-886.

Arnold, C. A. and L. Gunderson. 2013. Adaptive law and resilience. Environmental Law Reporter 43:10426-10443.

Benson, M. H. 2012. Intelligent tinkering: the Endangered Species Act and resilience. Ecology and Society 17(4): 28. http://dx.doi.org/10.5751/ES-05116-170428
Benson, M. H. and A. S. Garmestani. 2011a. Can we manage for resilience? The integration of resilience thinking into natural resource management in the United States. Environmental Management 48:392-399. http://dx.doi. org/10.1007/s00267-011-9693-5

Benson, M. H. and A. S. Garmestani. 2011b. Embracing panarchy, building resilience and integrating adaptive management through a rebirth of the National Environmental Policy Act. Journal of Environmental Management 92:1420-1427. http://dx.doi.org/10.1016/j.jenvman.2010.10.011

Bohensky, E., S. Stone-Jovicich, S. Larson, and N. Marshall. 2010. Adaptive capacity in theory and reality: implications for governance in the Great Barrier Reef Region. Pages 23-42 in D. Armitage and R. Plummer, editors. Adaptive capacity and environmental governance. Springer, Heidelberg, Germany. http://dx.doi.org/10.1007/978-3-642-12194-4 2

Conroy, M. J., C. R. Allen, J. T. Peterson, L. Pritchard, Jr., and C. T. Moore. 2003. Landscape change in the southern piedmont: challenges, solutions, and uncertainty across scales. Conservation Ecology 8(2): 3. [online] URL: http://www. consecol.org/Vol8/iss2/art3

Cosens, B. 2008. Resolving conflict in non-ideal, complex systems: solutions for the law-science breakdown in environmental and natural resource law. Natural Resources Journal 48:257.

Cosens, B. A., and M. K. Williams. 2012. Resilience and water governance: adaptive governance in the Columbia River basin. Ecology and Society 17(4): 3. http://dx.doi.org/10.5751/ ES-04986-170403

Craig, R. K. 2010. Stationarity is dead: long live transformation: five principles for climate change adaptation law. Harvard Environmental Law Review 34:9-74.

Cumming, G. S. 2013. Scale mismatches and reflexive law. Ecology and Society 18(1): 15. http://dx.doi.org/10.5751/ ES-05407-180115

de Loe, R. and R. Plummer. 2010. Climate change, adaptive capacity, and governance for drinking water in Canada. Pages 157-178 in D. Armitage and R. Plummer, editors. Adaptive capacity and environmental governance. Springer, Heidelberg, Germany. http://dx.doi.org/10.1007/978-3-642-12194-4 8

Dietz, T., E. Ostrom and P.C. Stern. 2003. The struggle to govern the commons. Science 302:1907-1912. http://dx.doi. org/10.1126/science.1091015

Flournoy A. C. and D. M. Driesen. 2010. Beyond environmental law: policy proposals for a better environmental future. Cambridge University Press, Cambridge, UK. http://dx.doi.org/10.1017/CBO9780511802591 
Garmestani, A. S. and M. H. Benson. 2013. A framework for resilience-based governance of social-ecological systems. Ecology and Society 18(1): 9. http://dx.doi.org/10.5751/ ES-05180-180109

Garmestani, A. S. and C. R. Allen. 2014. Social-ecological resilience and law. Columbia University Press, New York, New York, USA, in press.

Garmestani, A. S., C. R. Allen, and H. Cabezas. 2009. Panarchy, adaptive management and governance: policy options for building resilience. Nebraska Law Review 87:1036-1054.

Green, O. O., A. S. Garmestani, H. F. M. W. Van Rijswick, and A. M. Keessen. 2013. EU water governance: striking the right balance between regulatory flexibility and enforcement? Ecology and Society 18(2): 10. http://dx.doi.org/10.5751/ ES-05357-180210

Gunderson, L. 2013. How the Endangered Species Act promotes unintelligent, misplaced tinkering. Ecology and Society 18(1): 12. http://dx.doi.org/10.5751/ES-05601-180112

Gunderson, L. and C. S. Holling. 2002. Panarchy: understanding transformations in human and natural systems. Island Press, Washington, D.C., USA.

Holling C. S. 1973. Resilience and stability of ecological systems. Annual Review of Ecology and Systematics 4:1-23. http://dx.doi.org/10.1146/annurev.es.04.110173.000245

Holling, C. S. 2012. Response to "Panarchy and the Law". Ecology and Society 17(4): 37. http://dx.doi.org/10.5751/ ES-05402-170437

\section{http://dx.doi.org/10.5751/ES-05402-170437}

Hughes T. P., M. J. Rodrigues, D. R. Bellwood, D. M. Ceccarelli, O. Hoegh-Guldberg, L. McCook, N. Moltschaniwskyj, M. S. Pratchett, R. S. Steneck, and B. Willis. 2007. Phase shifts, herbivory, and the resilience of coral reefs to climate change. Current Biology 17:360-365. http://dx.doi. org/10.1016/j.cub.2006.12.049

Ilg, M. 2010. Complexity, environment, and equitable competition: a theory of adaptive rule design. Georgetown Journal of International Law 41:647-681.

Karkkainen, B. 2005. Panarchy and adaptive change: around the loop and back again. Minnesota Journal of Law, Science \& Technology 7:59-77.

Kofinas, G. P. 2009. Adaptive co-management in socialecological governance. Pages 77-101 in F. S. Chapin, G. P. Kofinas, and C. Folke, editors. Principles of ecosystem stewardship: Resilience-based natural resource management in a changing world. Springer, Heidelberg, Germany. http:// dx.doi.org/10.1007/978-0-387-73033-2 4
Lazarus, R. J. 2004. The making of environmental law. University of Chicago Press, Chicago, Illinois, USA. http:// dx.doi.org/10.7208/chicago/9780226470641.001.0001

Ruhl, J. B. 1999. The co-evolution of sustainable development and environmental justice: cooperation, then competition, then conflict. Duke Environmental Law \& Policy Forum 9:161-185.

Ruhl, J. B. 2005. Regulation by adaptive management: is it possible? Minnesota Journal of Law, Science \& Technology 7:21-57.

Ruhl, J. B. 2011. General design principles for resilience and adaptive capacity in legal systems - with applications to climate change adaptation. North Carolina Law Review 89:1373-1401.

Ruhl, J. B. 2012. Panarchy and the law. Ecology and Society 17(3): 31. http://dx.doi.org/10.5751/ES-05109-170331

Shapiro, S. A. and R. L. Glicksman. 2004. The APA and the back-end of regulation: procedures for informal adjudication. Administrative Law Review 56:1159-1178.

Walker, B. H. 2012. A commentary on "Resilience and water governance: adaptive governance in the Columbia River Basin". Ecology and Society 17(4): 29. http://dx.doi. org/10.5751/ES-05422-170429

Walters, C. and J. J. Maguire. 1996. Lessons for stock assessment from the northern cod collapse. Reviews in Fish Biology and Fisheries 6:125-137. http://dx.doi.org/10.1007/ BF00182340

Wandel, J. and G. P. Marchildon. 2010. Institutional fit and interplay in a dryland agricultural social-ecological system in Alberta, Canada. Pages 179-195 in D. Armitage and R. Plummer, editors. Adaptive capacity and environmental governance. Springer, Heidelberg, Germany. http://dx.doi. org/10.1007/978-3-642-12194-4_9

Young, O. R., L. A. King, and H. Schroeder. 2008. Institutions and environmental change. MIT Press, Cambridge, Massachusetts, USA. 